\title{
O AVESSO DA MARGINALIDADE: RELENDO JOÃO ANTÔNIO PELO DEBATE DA LITERATURA MARGINAL
}

\author{
Wagner Coriolano de Abreu $^{1}$
}

\begin{abstract}
Resumo: A aproximação entre João Antônio e os autores de literatura marginal tem marcado alguns trabalhos de pós-graduação nos departamentos de Letras, embora a noção de marginalidade presente nos itinerários poéticos aponte o afastamento entre os escritores. O artigo apresenta convergências e divergências da literatura de João Antônio com a literatura marginal periférica.
\end{abstract}

Palavras-Chave: Marginalidade, João Antônio, Literatura marginal, Crítica literária, Crítica cultural.

\begin{abstract}
The current rapprochement between João Antonio and the authors of marginal literature has marked academic works in the area of Literature, despite the fact that the notion of marginality present in the poetic itineraries points toward a gap between them. This article presents convergences and divergences perceived between João Antonio's and marginal and peripherical literature.
\end{abstract}

Keywords: Marginality, João Antônio, Marginal literature, Literary criticism, Cultural criticism.

A marginalidade é vista por João Antônio com senso crítico e situada em panorama amplo de leitura, razão pela qual recusa a ideia de escritor de marginalizados, reiterada em textos da imprensa e da crítica ${ }^{2}$. A necessidade de rever a posição de João Antônio, em face do debate da literatura marginal, requer retomar algumas elaborações sobre os marginalizados e o lugar que encontram dentro de sua produção ficcional. Nos anos 70, quando o escritor se con-

1 Bolsista de Pós-Doutorado do Programa de Doutorado da Associação Ampla entre a Universidade de Caxias do Sul (UCS) e UniRitter. Endereço eletrônico: coriolano3@gmail.com.

2 João Antônio, 59 anos, cronista dos marginalizados. O Globo, Rio de Janeiro, 1 nov. 1996, Obituário, p. 15. 
sagra como jornalista e contista, o ensaísta Robert Ponge escreve sobre a ideia de literatura marginal, destacando que se trata de uma tentativa de definição, dado que nos últimos anos que antecedem a sua reflexão o termo marginal passa a circular em numerosos campos do conhecimento humano. O artigo de Ponge enfatiza que "fora da economia, onde a escola marginal está histórica e precisamente definida e determinada, o termo marginal, apesar de sua utilidade e praticidade evidentes, tem levantado muitos problemas no seu uso pela sua falta de precisão, de cientificidade” (FERREIRA, 1981, p. 137).

As marcas do texto de João Antônio reaparecem de alguma forma nas principais obras relacionadas à periferia ou literatura marginal, quer pela temática, quer pela fatura literária na escrita da vida suburbana. Elas podem também ser reconhecidas em escritores contemporâneos não reunidos pela literatura marginal, mas produtores de obra voltada para a periferia, como Paulo Lins, com seu romance Cidade de Deus (1997), título que remete à reportagem feita por João Antônio, intitulada “Testemunho de Cidade de Deus”, cujo texto se encontra no livro Casa de loucos (1976).

Tanto no conto "Frio", publicado em Malagueta, perus e bacanaço (1963), como em “Guardador”, publicado em Abraçado ao meu rancor (1986), João Antônio introduz marcas da rua, da precariedade subjacente que aparece no tecido da cidade. Na rua vive o menino pretinho, engraxate na cidade de São Paulo, que não tem família e mora num porão, sob a guarda de um malandro. Na rua vive também o velho com cabeça branquejando, guardador de carros, que à noite se recolhe no oco de uma figueira e fica observando a lua no céu, solitário, numa praça da cidade do Rio de Janeiro. Sob a perspectiva da rua, a aproximação faz sentido, como se lê em dois contos de Ferréz: para a rua segue o ex-detento que narra o conto "O país das calças beges”, publicado em Grafias urbanas (MIGUEL, 2010); para a rua segue o exvendedor de algodão-doce, Marquinhos, onde acaba baleado por ladrões na pizzaria, no conto “Hoje tá fazendo um sol”, publicado em Cenas da favela (OLIVEIRA, 2007).

Do período entre o final dos anos 90 e primeira década do século 21, Reginaldo Ferreira da Silva, cognome Ferréz, realiza uma literatura centrada na periferia de São Paulo, reunindo escritores em torno de uma literatura de rua ou marginal (FERRÉZ, 2005, p. 10). Conforme Carlos Juliano Barros, a literatura marginal desponta no vazio ou ostracismo em que se encontra a obra de João Antônio, dado que se tornou desconhecido da posteridade, mesmo conside- 
Pontos de Interrogação, v. 3, n. 1, jan./jul. 2013

Revista do Programa de Pós-Graduação em Crítica Cultural

Universidade do Estado da Bahia (UNEB), Campus II - Alagoinhas - BA

rado pela crítica como um dos mais importantes escritores contemporâneos (BARROS, 2005, p. 42).

A ideia do paralelo entre João Antônio e a literatura marginal, conforme aponta Barros, reaparece em trabalhos de pesquisa acadêmica, como o de Érica Peçanha do Nascimento (2006) e de Rejane Pivetta de Oliveira (2011), que registram junto aos escritores da literatura marginal o nome de João Antônio, cuja obra se situa no marco de 1963 a 1996, anterior ao surgimento da literatura marginal de que tratam as referidas pesquisadoras. $\mathrm{O}$ afastamento entre os escritores, entretanto, desponta à medida que nos voltamos para a noção de marginalidade presente nos itinerários poéticos. Com estudo da fortuna crítica, produzida na década seguinte à morte de João Antônio, Roberta Pereira Pires recomenda ponderação quanto à imagem de marginal: “é importante verificar de que modo e em quais aspectos João Antônio pode ser considerado marginal” (PIRES, 2008, p. 58).

A emergência da sociedade de rua, com evidência a partir de escritores dos anos 60 , fez surgir uma literatura com interesse pela representação do morador de rua, da viração, do urbano como espaço de conflito, da disseminação do medo e ainda do debate em torno dos excluídos da cidadania. A plataforma literária de João Antônio, nesse sentido, pautou inicialmente pelos temas do homem marginalizado, de modo que a crítica acompanhou a trajetória de sua produção, dando ênfase ao caráter marginal de muitos de seus textos. Entretanto, escritos como “Afinação da arte de chutar tampinhas” e "Fujie”, do livro de estreia, e "Meus tempos de menino”, do livro Dama do encantado (1996), só para destacar alguns, ficam à margem do horizonte de leitura e fora do raio de alcance desta crítica.

A obra de João Antônio enquadra-se na noção de espelho da literatura, conforme aponta Regina Zilberman, ao tratar do percurso ficcional da literatura brasileira no século 20: “a literatura de ficção como um dos traços que compõem a face de um país que se procura em cada coisa que faz” (2001, p. 32). Do livro de estreia Malagueta, perus e bacanaço (1963) ao segundo livro, Leão-de-chácara (1975), o escritor dividiu-se entre a literatura e a efervescência do jornalismo, sua principal atividade profissional, exercendo o ofício em jornais consolidados e nos pequenos veículos, na imprensa nanica, como passou a referir a revistas e jornais combativos. 
Nos doze anos que separam o primeiro do segundo livro, não dorme em serviço. Ainda em 1975 aparece Malhação do Judas Carioca, reunião de textos de reportagem, de prosa ficcional e do manifesto Corpo-a-corpo com a vida. Em seguida, vieram Casa de loucos (1976), Calvário e porres do pingente Afonso Henriques de Lima Barreto (1977), Lambões de caçarola (1977) e Ô Copacabana (1978), apenas para destacar a produção em livro, sem contar as participações em veículos impressos e a maratona de conferências em universidades.

Com Dedo-duro (1982), reunião de narrativas ficcionais, João Antônio busca novos caminhos na literatura contemporânea, notabilizando-se como representante do proletariado lúmpen, o excluído por excelência das esferas de decisão, sejam políticas ou sociais. O patamar que atingiu dificilmente foi alcançado por outros ficcionistas, dada a forte clivagem social constatável no país, conforme a qual os oprimidos, especialmente quando pertencem às camadas populares, no campo ou na cidade, têm poucas oportunidades de se manifestar (ZILBERMAN, 2001, p. 34).

Se a obra de João Antônio apresenta-se marcada pela temática dos marginalizados, sua produção, todavia, engloba textos literários e jornalísticos que tratam de outras temáticas, como conflitos amorosos e perfil de gente renomada na cultura brasileira. Ao ser interpelado pelo jornalista Luiz Zanin Oricchio sobre sua linha de preferência pelos marginais, assim fala o escritor: "Bem, às vezes eu fico meio chateado com esse clichê de escritor de marginais" (ORICCHIO, 1999, p.23).

Com este estudo do avesso da marginalidade propomos encontrar algo que se perde da contribuição de João Antônio no debate da literatura marginal. E começamos pela mutação do sentido da palavra marginal ou marginalidade, dado que o escritor mapeia a cartografia dos marginalizados, enquanto que o manifesto “Terrorismo literário” - texto de apresentação dos escritores da literatura marginal - toma o termo com o sentido de pertencimento, colocando o marginal como alguém dono da voz e proponente de uma literatura:

Estamos na rua, loco, estamos na favela, no campo, no bar, nos viadutos, e somos marginais mas antes somos literatura, e isso vocês podem negar, podem fechar os olhos, virar as costas, mas, como já se disse, continuaremos aqui, assim como o muro social invisível que divide este país (FERRÉZ, 2005, p. 10).

Se alguns temas caros a João Antônio reaparecem na obra dos escritores da periferia como menino de rua (Frio), favela (Mariazinha Tiro a Esmo), periferia (Testemunho da Cida- 
Pontos de Interrogação, v. 3, n. 1, jan./jul. 2013

Revista do Programa de Pós-Graduação em Crítica Cultural

Universidade do Estado da Bahia (UNEB), Campus II - Alagoinhas - BA

de de Deus), morador de rua (Guardador), pequeno comércio (Mendigos e mafueiros) e subúrbio (Pingentes) - temas que atravessam a obra, o mesmo não acontece com o seu tratamento dedicado à marginalidade, ao submundo e ao povo. João Antônio reposiciona o problema nos seguintes termos:

Quem realmente não é marginal num país em que 2/3 da população estão marginalizados, em que a força de trabalho foi marginalizada e em que as verdadeiras reformas - urbanas e rurais - que desmarginalizariam essa população vem sendo cinicamente proteladas, adiadas ou ferozmente evitadas e omitidas? (FREITAS FILHO, 1980, p.58).

Em diversas ocasiões, o escritor aponta a questão da marginalidade: em artigos do jornal Correio do Povo e no manifesto “Corpo a corpo com a vida” (nos anos 70); nos contos do livro Dedo-Duro e de Abraçado ao meu rancor (nos anos 80); nas crônicas e contos dos livros Zicartola, Um herói sem paradeiro, Sete vezes rua, Dama do Encantado e em entrevistas concedidas à grande imprensa (nos anos 90).

Partindo das referências que o escritor faz à marginalidade e aos marginalizados, recorremos às notas sobre o conceito de marginalidade de Aníbal Quijano, publicadas em Populações “marginais”, livro organizado por Luiz Pereira em 1978. Quijano afirma que a condição da marginalidade tem a ver com

o fato de se pertencer ao mesmo tempo a vários mundos culturais, sem se estar incorporado plenamente a nenhum deles em particular, ou seja, o fato de se habitar uma zona cultural situada tanto dentro como fora das culturas em conflito (PEREIRA, 1978, p.16).

Por este viés, a marginalidade revela-se como uma forma de resistência, leitura que aparecerá na análise que Regina Zilberman faz dos contos de João Antônio, dando uma visada sobre a constante temática do escritor, de Malagueta, perus e bacanaço (1963) a Abraçado ao meu rancor (1986). De uma ponta a outra, se constata nestas obras a presença de protagonistas ligados a um tipo de vida que não se fixa em parte alguma, seres ambulantes que revelam a condição de desenraizamento social, de quebra das convenções e incapacidade de adaptação a um padrão consolidado de vida (ZILBERMAN, 1986).

A conferência de Sergius Gonzaga, “Literatura marginal”, proferida em 1977, relaciona o termo marginalidade a marginal, que

vulgarizou-se no universo brasileiro a partir da década de 50, quando os planos desenvolvimentistas geraram uma consciência eufórica do progresso. [...] Eram conhecidos como marginais, os habitantes das favelas urbanas, que o projeto de metas havia multiplicado (FERREIRA, 1981, p.148). 
Gonzaga antecipa questões que retornam no atual debate sobre a literatura marginal: primeiro que "a palavra marginal associou-se à produção artística, principalmente a literária, ultrapassando tanto o seu significado pejorativo quanto o econômico" (Idem, p. 148). Esta ideia é retomada por Rejane Pivetta de Oliveira, que lança questionamentos à literatura marginal periférica a partir da teoria literária.

Sergius Gonzaga, em seguida, aponta tendências nas correntes autodenominadas marginais, antecipando o estudo de Érica P. do Nascimento que, em sua dissertação, trabalha a atuação político-cultural dos escritores da periferia. E indica elementos que dialogam com o estudo de Roberta Pereira Pires, que trabalha a fortuna crítica de João Antônio, a partir das reedições póstumas, situando o escritor como pertencente à literatura marginal pela escolha de protagonistas, situações e cenários daquele universo.

Atualmente, a pesquisa acadêmica tem dado contribuição direcionada ao debate das perspectivas apontadas pela expressão, em alguns casos colocando-a na moldura de literatura contemporânea, orientação que, a nosso ver, melhor situa este ramo da produção literária. A denominação literatura marginal e sua recepção crítica estão sintetizadas no estudo de Rogério de Souza Silva (2011), no qual examina dois romances de literatura marginal e um romance contemporâneo, consagrado para além da moldura marginal.

A síntese da denominação aponta a existência de um controle (dos que têm poder simbólico de campo) que impediu a legitimação desta literatura marginal, cujo projeto "vai além do literário, pois busca se constituir em porta-voz estético e ideológico dos que sempre foram silenciados” (SILVA, 2011, p. 28). É com esta perspectiva que alguns autores se posicionam frente ao debate da literatura brasileira contemporânea, o que também indica sua divergência com a literatura de João Antônio, que se insere no circuito oficial por meio da editora Civilização Brasileira e se engaja nos debates culturais de sua época.

Sob a denominação poesia marginal, o ensaísta registra que ela surge como movimento cultural de uma juventude descontente com posições políticas e culturais após 64. Mesmo com o golpe militar e o fim das liberdades civis, a presença cultural de esquerda cresce até 68, quando o governo impõe o Ato Institucional n ${ }^{\circ}$. Muitos dos poetas do período se reuniram no encontro Expoesia I, realizado na Pontifícia Universidade do Rio de Janeiro, em 1973 (SILVA, 2011, p. 32). Observa nesta poesia que o "registro do cotidiano quase em estado bru- 
Pontos de Interrogação, v. 3, n. 1, jan./jul. 2013

Revista do Programa de Pós-Graduação em Crítica Cultural

Universidade do Estado da Bahia (UNEB), Campus II - Alagoinhas - BA

to informa os poemas e, mais que um procedimento literário inovador, revela os traços de um novo tipo de relação com a literatura” (Idem, p. 34). A perspectiva da literatura marginal dos anos 70 diverge do sentido atribuído pelos autores marginais do século 21. Rogério de Souza Silva afirma que

primeiramente, o contexto político e cultural se alterou. Não vivemos mais num estado de exceção. Segundo, a indústria cultural se consolidou deixando pouco espaço para produções alternativas. Terceiro, os autores da literatura marginal não são membros da classe média (Idem, p. 34).

O ensaísta questiona o estatuto da literatura e sua recepção, destacando que "a diferenciação entre literatura e outras formas de produção cultural é sempre condicionada historicamente” (Idem, p. 36). Mesmo reconhecendo que o objeto de seu estudo é literário, ele se propõe a tratá-lo como fenômeno cultural em sentido amplo. E sua proposta de recepção da literatura marginal inicialmente se estabelece não por meio de um dos autores do século 21 (que pode ser favelado, ex-presidiário, detento, rapper e grafiteiro), mas pela análise e recepção do romance Cidade de Deus (1997), escrito por Paulo Lins, autor assimilado pelo cânone do eixo Rio-São Paulo.

Se a amplitude da expressão, conforme assinala Érica do Nascimento, marca a trajetória de muitos escritores brasileiros, notadamente aqueles que estiveram associados a ela e se tornaram referências para os escritores da periferia (NASCIMENTO, 2006, p. 12), se torna necessário indicar alguns caminhos de leitura na obra de João Antônio que podem concernir a este debate $^{3}$. Um estudo da obra de João Antônio pode desencadear uma série de conexões entre os dados dispersos de sua obra e as leituras e não leituras que teve, esclarecendo inclusive a aproximação sumária entre autor e obra. Por ter tratado de jogadores de sinuca, malandros, guardadores de automóvel, meninos de rua e outras personagens da arraia miúda, por ter se pronunciado de modo a colocar-se ao lado destes tipos humanos, o autor é tido como marginal, o que é reforçado, quando se toma seu comportamento pessoal, como muitas vezes acontece. O comportamento de João Antônio, no entanto, era mais um artifício de sua arte,

3 Entre os escritores que se tornaram referência aos escritores da periferia, Nascimento afirma que "Um deles é João Antônio (1937-1996), que entre os anos 1960 e 1970 lançou obras (como Malagueta, perus e bacanaço) que buscaram retratar as experiências e práticas de lazer (os jogos de sinuca, por exemplo) dos membros das classes populares, dos “malandros”, contraventores e trabalhadores” (NASCIMENTO, 2006, p. 12). 
como na cena em que aparece na redação de um jornal, todo enfaixado, inventando a história de atropelamento, que ao final lhe rende uns dias de folga (CASTELLO, 1999, p. 45).

A literatura de João Antônio proporciona uma visão acerca dos problemas sociais enfrentados pelo povo brasileiro, sobretudo nas cidades, onde as condições de vida são precárias e as estruturas não contribuem para se realizar um projeto de cidadania. Representante de uma gente que não é ouvida e percebida pelas autoridades, o escritor manifestou sua visão através da eleição de tipos sociais marginalizados, como personagens de contos e crônicas, e de textos jornalísticos e entrevistas, em que procura interpretar a situação do homem que não consegue sobreviver em face das circunstâncias sociopolíticas, como no manifesto Corpo-a-corpo com $a$ vida (ANTÔNIO, 1975). As posições que João Antônio assumiu diante da deterioração do produto cultural brasileiro, atacando diretamente quem deveria responder pela calamidade, sobretudo a imprensa, ajudaram a formar a imagem de escritor de marginais ou "Rabelais da boca do lixo”, como a imprensa o rotulou.

Em entrevista concedida aos organizadores do livro Anos 70 (FREITAS FILHO, 1980), João Antônio convida o leitor para a leitura literária:

O que me parece que esta fatia de “críticos” está esquecendo é de que precisamos reatar certas raízes brasileiras lá atrás: Manoel Antônio de Almeida, Afonso Henriques de Lima Barreto, Mário de Andrade, Oswald de Andrade, Graciliano Ramos e outros. Outro fator que é necessário questionar no país é a chamada marginalidade.

Penso que deveria ser esta tarefa o objeto de nossa preocupação.

\section{REFERÊNCIAS}

ANTÔNIO, João. A arte tem dívida com a realidade. Jornal do Brasil, Rio de Janeiro, 8 jun. 1996.

ANTÔNIO, João. O autor e sua obra. In: Meninão do caixote. São Paulo: Atual, 1991.

ANTÔNIO, João. Lambões do Beco da Onça. Correio do Povo, Porto Alegre, 5 nov. 1977.

ANTÔNIO, João. Malagueta, perus e bacanaço. São Paulo: Civilização Brasileira, 1963.

ANTÔNIO, João. Leão-de-chacára. Rio de Janeiro: Civilização Brasileira, 1975.

ANTÔNIO, João. Malhação do Judas Carioca. Rio de Janeiro: Civilização Brasileira, 1975.

ANTÔNIO, João. Casa de loucos. 2. ed. Rio de Janeiro: Civilização Brasileira, 1976.

ANTÔNIO, João. Ô Copacabana. Rio de Janeiro: Civilização Brasileira, 1978. 
ANTÔNIO, João. Dedo-duro. Rio de Janeiro: Record, 1982.

ANTÔNIO, João. Abraçado ao meu rancor. Rio de Janeiro: Guanabara, 1986.

ANTÔNIO, João. Meninão do caixote. 6 ed. São Paulo: Atual, 1991.

ANTÔNIO, João. Zicartola e que tudo mais vá para o inferno! São Paulo: Scipione, 1991.

ANTÔNIO, João. Guardador. Rio de Janeiro: Civilização Brasileira, 1992.

ANTÔNIO, João. Um herói sem paradeiro: vidão e agitos de Jacarandá, poeta do momento. 4 ed. São Paulo: Atual, 1993.

ANTÔNIO, João. Dama do Encantado. São Paulo: Nova Alexandria, 1996.

ANTÔNIO, João. Sete vezes rua. São Paulo: Scipione, 1996.

BARROS, Carlos Juliano. Genial e desconhecido. Problemas Brasileiros, SESC São Paulo, mar./abr. 2005, p. 42-45.

CASTELLO, José. A arte de ser João. In: Inventário das sombras. Rio de Janeiro: Record, 1999. p.39-55.

FERREIRA, João-Francisco (Coord.). Crítica literária em nossos dias e literatura marginal. Porto Alegre: Editora da Universidade, 1981.

FERRÉZ. Literatura marginal: talentos da escrita periférica. Rio de Janeiro: Agir, 2005.

FREITAS FILHO, Armando; HOLLANDA, H. B. de; GONÇALVES, M. A. Anos 70 - literatura. Rio de Janeiro: Europa, 1980, v. 2.

GONZAGA, Sergius. Literatura marginal. In: FERREIRA, João-Francisco (Coord.). Crítica literária em nossos dias e literatura marginal. Porto Alegre: Editora da Universidade, 1981. p. 143-153.

JOÃO ANTÔNIO, 59 anos, cronista dos marginalizados. O Globo, Rio de Janeiro, 1 nov. 1996, Obituário, p. 15.

LINS, Paulo. Cidade de Deus. São Paulo: Companhia das Letras, 1997.

MIGUEL, Adilson (Org.). Grafias urbanas: antologia de contos contemporâneos. São Paulo: Scipione, 2010.

NASCIMENTO, Érica Peçanha do. Literatura marginal: os escritores da periferia entram em cena. 211 p. Dissertação (Mestrado) - Faculdade de Filosofia, Letras e Ciências Humanas da Universidade de São Paulo, São Paulo. 2006.

OLIVEIRA, Nelson (Org.). Cenas da favela: antologia. Rio de Janeiro: Geração Editorial, 2007.

OLIVEIRA, Rejane Pivetta de. Literatura marginal: questionamentos à teoria literária. Ipotesi, Juiz de Fora, v. 15, n. 2, p. 31-39, jul./dez. 2011.

ORNELLAS, Clara Ávila. O subúrbio como centro do mundo: Lima Barreto e João Antônio. Navegações, Porto alegre, v. 3, n. 1, p. 7-16, jan./jun. 2010.

ORICCHIO, Luiz Zanin. Eu queria mesmo é ser um homem sem profissão. Entrevista com João Antônio. Muito +, São Paulo, p. 20-27, dez. 1999/jan. 2000. 
PEREIRA, Luiz (Org.). Populações “marginais”. São Paulo: Duas Cidades, 1978.

PIRES, Roberta Pereira. Vida e literatura: estudo da fortuna crítica de João Antônio, de 1996 a 2006. 127 p. Dissertação (Mestrado) - Faculdade de Ciências e Letras de Assis, Universidade Estadual Paulista, Assis. 2008.

QUIJANO, Aníbal. Notas sobre o conceito de marginalidade social. In: PEREIRA, Luiz (Org.). Populações “marginais”. São Paulo: Duas Cidades, 1978.

SILVA, Rogério de Souza. Cultura e violência: autores, polêmicas e contribuições da literatura marginal. São Paulo: Annablume, 2011.

ZILBERMAN, Regina. João Antônio: contos, com velhos heróis. Jornal da Tarde, São Paulo, 30/08/1986.

ZILBERMAN, Regina. O espelho da literatura. Revista Vox, Porto Alegre, v. 3, p. 32-34, jan. 2001.

Recebido em: 20 de agosto de 2013.

Aceito em: 15 de setembro de 2013. 